\title{
Clinical benefit in Phase-I trials of novel molecularly targeted agents: does dose matter?
}

\author{
S Postel-Vinay',2, H-T Arkenau',2, D Olmos', J Ang', J Barriuso', S Ashley', U Banerji', J De-Bono', I Judson' \\ and S Kaye ${ }^{*, 1}$ \\ 'Royal Marsden Hospital and The Institute of Cancer Research, Drug Development Unit, Downs Road, SM2 5PT, Sutton, UK
}

Phase-I trials traditionally involve dose-escalation to determine the maximal tolerated dose (MTD). With conventional chemotherapy, efficacy is generally deemed to be dose-dependent, but the same may not be applicable to molecularly targeted agents (MTAs). We analysed consecutive patients included in Phase-I trials at the Royal Marsden Hospital from 5 January 2005 to 6 June 2006. We considered only trials of monotherapy MTAs in which the MTD was defined. Three patient cohorts (A, B, and C) were identified according to the dose received as a percentage of the final trial MTD $(0-33 \%, 34-65 \%,>66 \%)$. Potential efficacy was assessed using the non-progression rate (NPR), that is, complete/partial response or stable disease for at least 3 months by RECIST. A total of I 35 patients having progressive disease before enrolment were analysed from 15 eligible trials. Median age was 57 years (20-86); male: female ratio was I.8: I. Cohort A, B, and C included 28 (21\%), 22 (16\%), and 85 (63\%) patients; NPR at 3 and 6 months was $21 \%$ and $11 \%(A), 50 \%$ and $27 \%(B), 31 \%$ and $14 \%(C)$, respectively, $P=0.9$. Median duration of non-progression ( 17 weeks; $95 \%$ $\mathrm{Cl}=13-22$ ) was not correlated with the MTD level, $P=0.9$. Our analysis suggests that the potential for clinical benefit is not confined to patients treated at doses close to the MTD in Phase-l trials of MTAs.

British Journal of Cancer (2009) 100, I373- 1378. doi: I0. I038/sj.bjc.6605030 www.bjcancer.com

(c) 2009 Cancer Research UK

Keywords: Phase-I trial; molecularly targeted agents; maximal tolerated dose; non-progression rate; clinical benefit

The aim of Phase-I trials is to determine the optimal recommended Phase-II dose (RP2D) of a new compound for further clinical investigation. For cytotoxic drugs, this dose traditionally corresponds to the highest dose associated with an acceptable level of toxicity and is derived from clinical data and preclinical dose-toxicity and dose-activity studies (Korn et al, 2001). For conventional cytotoxic agents, in vitro data and preclinical models using cell lines showed that higher exposure to a drug generally increases tumour cell kill; this dose-response relationship was extrapolated to humans and oncologists have widely adhered to the principle that 'more is better'. Indeed, recent observations showed that the majority of responses occurred at $75-125 \%$ of the RP2D, and that the RP2D was usually the maximal tolerated dose (MTD) (Von Hoff and Turner, 1991; Itoh et al, 1994; Parulekar and Eisenhauer, 2004).

Unlike classical chemotherapy agents, new molecularly targeted agents (MTA) are based on different mechanisms and are often considered to be cytostatic rather than cytotoxic. Clinically, this implies that the radiological evaluation of their efficacy by RECIST criteria should include not only a reduction in tumour size, but also non-progression (NP) or disease stabilisation. Therefore, the

\footnotetext{
* Correspondence: Professor S Kaye; E-mail: stan.kaye@rmh.nhs.uk This study was presented in the oral presentation session at the ASCO 2008 conference, Chicago.

2 These authors contributed equally to this work.

Received 9 October 2008; revised II March 2009; accepted I8 March 2009
}

NP rate (NPR), defined as tumour response plus stable disease (SD), could be a relevant measure of response as well as a potential indicator for clinical benefit.

These novel MTA are often characterised by clinically relevant organ toxicities, which differ from the antiproliferative toxicities seen with cytotoxic chemotherapy, and MTD is not always reached (Booth et al, 2008). Thus, the determination of the RP2D based only on toxicity as surrogate marker for activity in the conventional Phase-I setting may be inappropriate for these agents. Moreover, it is unclear whether the RP2D based on toxicity is close to the optimal active dose, as this is derived from a linear dose-efficacy relationship assumption, which may not be relevant for these novel compounds (Parulekar and Eisenhauer, 2004; Cannistra, 2008). Therefore, some authors have advocated establishing a dose range, combining toxicity data - defining the upper limit - and pharmacodynamic and pharmacokinetic data - defining lower dose levels, which could be tested in a randomised Phase-II trial (Booth et al, 2008).

Although it is widely agreed that demonstration of anti-tumor activity is not the primary endpoint of Phase-I trials, both patients and physicians hope for benefits from treatment : a discussion about the chances of benefit - that is, tumour response or disease control - is always included in the conversation with Phase-I candidates (Agrawal and Emanuel, 2003). The ethics and individual merits of Phase-I trials have been extensively debated during the 'era' of cytotoxic drugs development, and it has been reported that up to $60 \%$ of the patients could be treated at subtherapeutic dose levels (Agrawal and Emanuel, 2003; Koyfman et al, 2007). Efforts to minimise the number of patients treated at 
sub-therapeutic doses and required to reach the MTD have lead to the development of different trial designs such as the continuous reassessment method (Potter, 2002).

The purpose of this study was to investigate whether, in the era of MTA, the chance of benefit in Phase-I trials depended on the dose received, that is, was there any detriment for patients enroled at early dose levels.

\section{PATIENTS AND METHODS}

\section{Study design, patients, and trials eligibility criteria}

This retrospective study considered all consecutive patients evaluable for response and treated in at least one Phase-I trial in the Drug Development Unit at The Royal Marsden Hospital (RMH), United Kingdom, from 5 January 2005 to 6 June 2006. From our database, we selected only patients who were included in trials meeting the following criteria: (1) Trials studying an MTA an MTA being defined as any agent with any extra- or intracellular target different from those associated with conventional chemotherapy (DNA, tubulin, or cell division machinery); actual tumour shrinkage as opposed to stasis in an experimental model was not a pre-requisite; (2) Trials in which the MTD was described; (3) Trials evaluating an MTA in monotherapy (combinations with conventional chemotherapy or radiotherapy were excluded); and (4) Trials in which the dose escalation method allowed an easy comparison in terms of MTD percentage. All MTD levels were defined individually for each trial on the basis of the protocol MTD definition. All the patients in our analysis had evidence of disease progression before trial entry. Several clinical parameters were collected at study entry, including tumour type, age, sex, ECOG performance status, full blood count, biochemistry (lactate dehydrogenase, and albumin), number and sites of metastasis, and number of earlier systemic cancer treatments. Using these data, we were able to apply our recently validated $\mathrm{RMH}$ prognostic score (Arkenau et al, 2009).

We analysed the NPR, a combination of complete response, partial response (PR), and $\mathrm{SD}$, at the first assessment after trial entry, and at 3 and 6 months. We considered the NPR at $>3$ months as a potential indicator for clinical benefit.

All Phase-I trials included in this analysis were approved by the Research and Development Committee and Ethics Committee of the RMH. This analysis received approval of the RMH audit committee.

\section{Patients' evaluation and follow-up}

All patients underwent regular follow-up and assessment of the disease was carried out by CT (RECIST criteria (Therasse et al, 2000) before trial entry, and every 6 to 8 weeks depending on protocol requirements. For prostate cancer patients, PSAWG criteria (Bubley et al, 1999) were allowed for the definition of progressive disease, but not for disease response.

\section{Statistical analysis}

Three cohorts (A: $0-33 \%, \mathrm{~B}: 34-66 \%$, and C: $>67 \%$ of the MTD) were defined according to the percentage of the final MTD received by each patient. The percentage of MTD was not considered as a continuous variable, as the distribution of the different dose levels did not follow a regular pattern between 0 and $100 \%$ of the MTD. The Kaplan-Meier method and log-rank trend tests were used to compare the NPR, progression-free survival (PFS), and overall survival (OS) for all the patients between the three cohorts with a threshold for significance of $P=0.05$. PFS and OS for all patients were measured from trial entry until documented progression (by RECIST or PSAWG criteria) and death, respectively. For relevant patients, the duration of NP and survival were measured from the first administration of the study drug. The Kendall- $\tau$ correlation test was used to compare the distribution of the RMH Prognostic Score between the three cohorts. Statistics were carried out using the SPSS-Program (version 15.0, Chicago, IL, USA). The cut-off date for the present analysis was 7 July 2007.

\section{RESULTS}

\section{Trials Characteristics}

Between 5 January 2005 and 6 June 2006, 29 Phase-I trials (252 patients) were open for recruitment in our unit. We excluded 14 trials (117 patients) based on the earlier defined trial eligibility criteria (Figure 1): 10 trials involved conventional chemotherapy or radiotherapy in combination with an MTA; two trials investigating a virus used a logarithmic dose-escalation scales; two trials involving MTA did not reach the MTD.

The evaluable 15 trials (135 patients) investigated a variety of MTAs including epithelial growth factor receptor inhibitors, antiangiogenic agents, heat shock protein (HSP90) inhibitors, insulinlike growth factor receptor inhibitors, poly(ADP-ribose) polymerase inhibitors, or epigenetic modulators (Table 1). In total, 12 trials investigated small molecule tyrosine kinase inhibitors. For 12 trials (113 patients), the MTD was defined as the highest dose level below that at which fewer than 2 or more patients experience a DLT' and for three trials (22 patients), the MTD was defined as 'the dose at which at least 2 out of 6 patients experience a DLT'. Overall, the median number of dose levels was 5 (range: 4-9).

\section{Patients' characteristics}

The characteristics of the 135 eligible patients were as follows: the median age was 57 years (range: $20-86$ ) with a male: female ratio

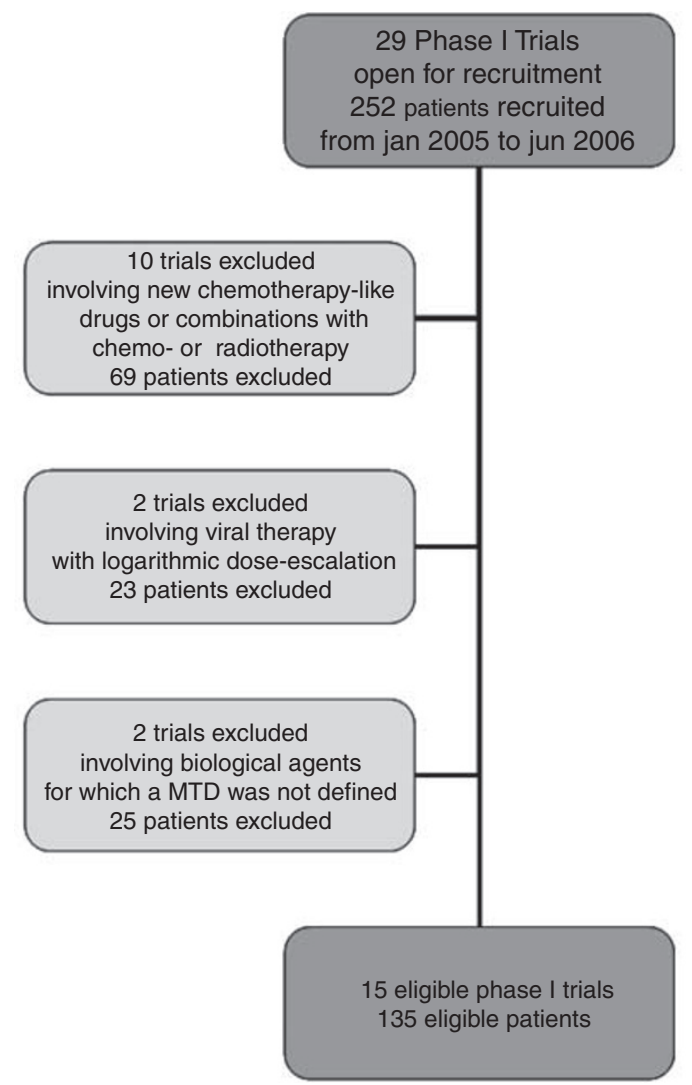

Figure I Overview of trial/patient database. 
Table I Trials' characteristics

\begin{tabular}{|c|c|}
\hline $\begin{array}{l}\text { Number of trials } \\
\text { Trials' characteristics }\end{array}$ & $\begin{array}{c}N=15 \\
N\end{array}$ \\
\hline \multicolumn{2}{|l|}{ Drug target } \\
\hline EGFR & 2 \\
\hline VEGFR2 & 2 \\
\hline VEGF & I \\
\hline HSP9O & I \\
\hline IGF-IR & I \\
\hline HDAC & 1 \\
\hline DNA methytransferase & 1 \\
\hline PARP & 1 \\
\hline TRAIL-R2 & i \\
\hline $5 \alpha$-hydroxylase/CI7,20lyase & 1 \\
\hline Rho-GTP dependant factor & 1 \\
\hline Farnesyl transferase & 1 \\
\hline Aminopeptidase & 1 \\
\hline \multicolumn{2}{|l|}{ Class of agent } \\
\hline Small molecule TKls & 12 \\
\hline Monoclonal antibodies & 2 \\
\hline ASO & I \\
\hline \multicolumn{2}{|l|}{ Number of dose levels } \\
\hline 4 dose levels & 3 \\
\hline 5 dose levels & 6 \\
\hline 6 dose levels & 2 \\
\hline 8 dose levels or more & 4 \\
\hline \multicolumn{2}{|l|}{ Dose escalation method } \\
\hline Modified fibonacci & I \\
\hline Accelerated titration & 9 \\
\hline Pre-established dose levels increments & 5 \\
\hline
\end{tabular}

ASO = antisense oligodeoxynucleotide; EGFR = epithelial growth factor receptor; HDAC = histone deacetylase; HSP90 = heat shock protein inhibitor, IGF-IR = insulinlike growth factor receptor inhibitor; PARP $=$ poly(ADP-ribose) polymerase inhibitor; TKls = tyrosine kinase inhibitors; TRAIL-R2 = TNF-related apoptosis inducing ligandreceptor 2; VEGF = vascular endothelial growth factor; VEGFR2 = vascular endothelial growth factor receptor 2 .

of $1.8: 1$. The majority of patients had an ECOG PS of $1(63 \%)$ and only $10 \%$ of patients had a PS of 2 . The median number of earlier therapies was 2 (range: $0-8$ ) and patients presented with a broad spectrum of tumour types (Table 2 ).

\section{Cohorts}

Cohorts A, B, and C included 28 (21\%), 22 (16\%), and 85 (63\%) patients, respectively. The larger number of patients included in cohort $\mathrm{C}$ is related to the fact that most trials dose expanded at the MTD level. The patients' characteristics and the RMH prognostic score were not significantly different in the three cohorts reflected by a Kendall- $\tau$ coefficient of $-0.032(P=$ NS) (Table 3$)$.

\section{Responses, non-progression rate, and survival}

Non-progression rate The median follow-up time of this analysis was 69 weeks. A total of 23 patients (17\%) were not evaluable for disease response because of early clinical progression (13 patients), toxicity (five patients including three DLTs), or death (five patients). Nine patients with prostate cancer progressed on PSA measurement according to PSAWG criteria, without radiological progression.

The NPR for the entire population, at 3 months and 6 months was $32 \%$ (43 patients) and $16 \%$ (21 patients), respectively. The NPR for the three cohorts at 3 and 6 months was not significantly different, $P=0.9$ (Cohort A: $21 \%$ (6 patients) and $11 \%$ (3 patients); Cohort B: $50 \%$ (11 patients) and 27\% (6 patients); Cohort C: $31 \%$ (26 patients) and $14 \%$ (12 patients), respectively (Table 3$)$. The
Table 2 Patients' characteristics

\begin{tabular}{|c|c|}
\hline $\begin{array}{l}\text { Number of patients } \\
\text { Patients' characteristics }\end{array}$ & $\begin{array}{c}N=135 \\
\text { Total (\%) }\end{array}$ \\
\hline \multicolumn{2}{|l|}{ Age } \\
\hline Median (range) & $57(20-86)$ \\
\hline \multicolumn{2}{|l|}{ Sex } \\
\hline Male & $87(64 \%)$ \\
\hline Female & $48(36 \%)$ \\
\hline \multicolumn{2}{|l|}{ Performance status (ECOG) } \\
\hline 0 & $37(27 \%)$ \\
\hline 1 & 85 (63\%) \\
\hline 2 & $13(10 \%)$ \\
\hline \multicolumn{2}{|l|}{ Earlier therapy } \\
\hline Median (range) & $2(0-8)$ \\
\hline \multicolumn{2}{|l|}{ Tumour type } \\
\hline Breast and gynaecological & $24(18 \%)$ \\
\hline Prostate & $21(16 \%)$ \\
\hline Sarcoma & $21(16 \%)$ \\
\hline Thoracic & $20(15 \%)$ \\
\hline Gastro-intestinal & $15(11 \%)$ \\
\hline Renal & $12(8 \%)$ \\
\hline Melanoma & $5(4 \%)$ \\
\hline Others & $17(13 \%)$ \\
\hline \multicolumn{2}{|l|}{ RMH Prognostic score } \\
\hline 0 & $16(12 \%)$ \\
\hline 1 & $38(28 \%)$ \\
\hline 2 & $51(38 \%)$ \\
\hline 3 & $30(22 \%)$ \\
\hline
\end{tabular}

$\mathrm{ECOG}=$ Eastern cooperative oncology group; $\mathrm{RMH}=$ Royal Marsden Hospital prognostic score.

Table 3 Patients' distribution and MTD cohorts

\begin{tabular}{|c|c|c|c|c|}
\hline & Cohort A & Cohort B & Cohort C & Total \\
\hline Number of patients (\%) & & & & \\
\hline Gender ( $\mathrm{n}$ & $28(21 \%)$ & $22(16 \%)$ & 85 (63\%) & 135 \\
\hline Age (med & $15 / 13^{*}$ & 13/9* & $59 / 26 *$ & $87 / 48$ \\
\hline - & $60(20-83)$ & $56(27-77)$ & $57(25-86)$ & $57(20-86)$ \\
\hline $\begin{array}{l}\text { ECOG } 0 \\
\text { ECOG } 1 \\
\text { ECOG } 2\end{array}$ & $\begin{array}{l}6 * \\
17 * \\
5 *\end{array}$ & $\begin{array}{l}6 * \\
12 * \\
2 *\end{array}$ & $\begin{array}{l}22 * \\
51^{*} \\
3 *\end{array}$ & $\begin{array}{l}34 \\
80 \\
10\end{array}$ \\
\hline $\begin{array}{l}\text { RMH Prognostic score } \\
0-1 \\
2-3\end{array}$ & $\begin{array}{l}10(36 \%)^{\dagger} \\
18(64 \%)^{\dagger}\end{array}$ & $\begin{array}{l}9(41 \%)^{\dagger} \\
13(59 \%)^{\dagger}\end{array}$ & $\begin{array}{l}35(40 \%)^{\dagger} \\
51(60 \%)^{\dagger}\end{array}$ & $\begin{array}{l}54(40 \%) \\
81(60 \%)\end{array}$ \\
\hline $\begin{array}{c}\text { Non-progression rate } \\
\text { 3-month NPR } \\
\text { 6-month NPR }\end{array}$ & $\begin{array}{l}6(21 \%)^{\ddagger} \\
3(11 \%)^{\ddagger}\end{array}$ & $\begin{array}{l}\text { II }(50 \%)^{\ddagger} \\
6(27 \%)^{\ddagger}\end{array}$ & $\begin{array}{l}26(31 \%)^{\ddagger} \\
12(14 \%)^{\ddagger}\end{array}$ & $\begin{array}{l}43 / 135(32 \%) \\
21 / 135(16 \%)\end{array}$ \\
\hline
\end{tabular}

Objective responses

$$
\text { I } 3 \quad \text { । } 5
$$

$E C O G=$ Eastern cooperative oncology group; $M T D=$ maximal tolerated dose; $\mathrm{RMH}=$ Royal Marsden Hospital, NPR $=$ non-progression rate. ${ }^{*} P=0.1 .{ }^{\dagger} P=0.7$. ${ }^{\ddagger} P=0.9$.

results of patients with no progression at 3 months are shown as a waterfall plot, in Figure 2. The median duration of NP for all patients was 17 weeks (95\% CI: 13-22) (Cohort A: 23 weeks (95\% 


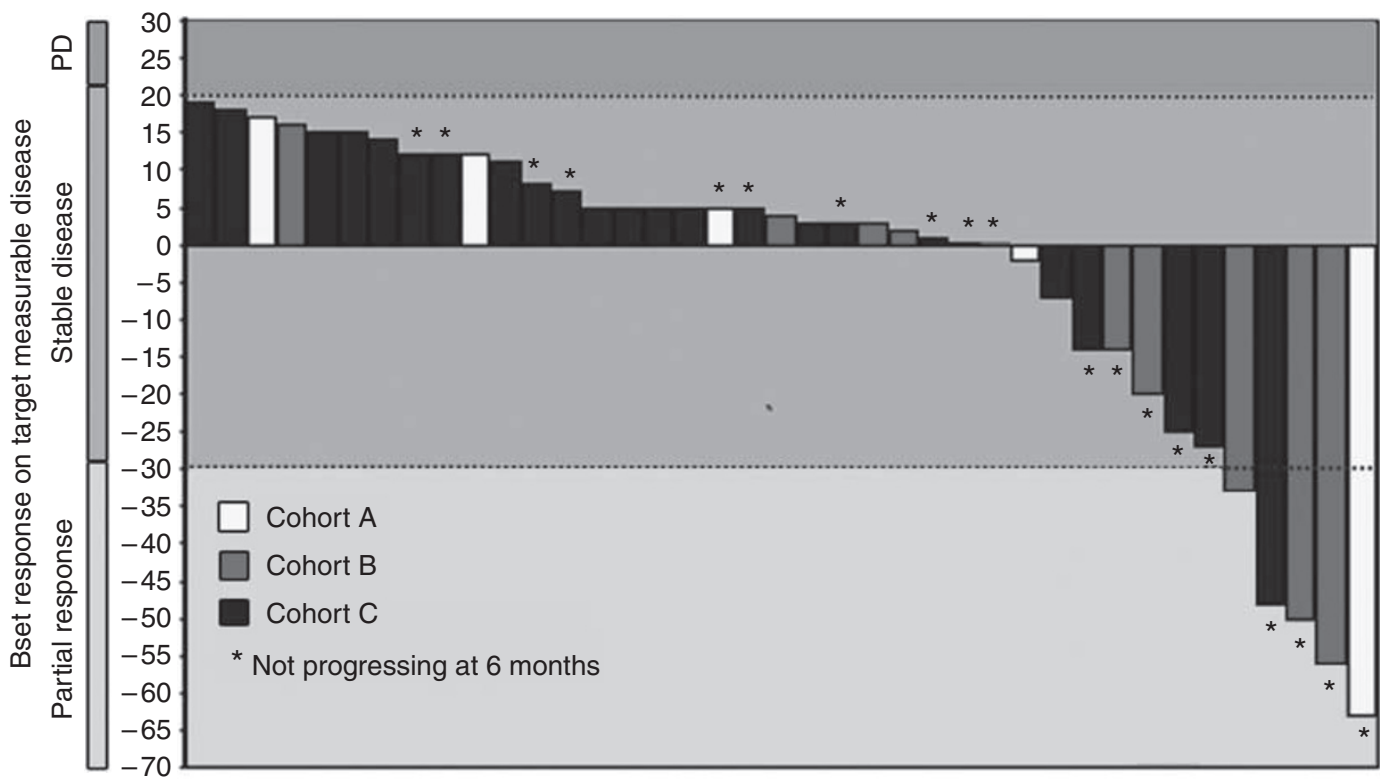

Figure 2 Best response at 3 months (Cohort A, B, and C). This waterfall plot represents the patients remaining progression free during the first 3 months on treatment; the column's colour corresponds to the dose-level cohort.

CI: $10-36)$; Cohort B: 19 weeks (95\% CI: 9-30); Cohort C: 15 weeks (95\% CI: $12-18)$ ), $P=0.9$. Prolonged NP ( $>6$ months) were seen in patients included in nine different trials, each of them comprising between 4 and 9 dose levels.

Responses Overall, five patients experienced PR (one in cohort A, three in cohort $\mathrm{B}$, and one in cohort $\mathrm{C}$ ). They were included in three different trials, comprising of 5, 4, and 8 dose levels.

Progression-free survival The median PFS was 10 weeks (95\% CI: $8-12$ ) for the entire population (Cohort A: 6 weeks (95\% CI: 5-7); Cohort B: 13 weeks (95\% CI: 8-17); Cohort C: 10 weeks (95\% CI: $8-12)), P=0.09$, Figure 3A.

Overall survival Overall survival was 38 weeks (95\% CI: 27-49) for the entire population and was not different between the three cohorts (Cohort A: 30 weeks (CI 95\% 18-43); Cohort B: 48 weeks (CI 95\%, 28-68); Cohort C: 41 weeks (CI 95\% 28-54)), $P=0.7$, Figure 3B.

\section{DISCUSSION}

Phase-I trials have been developed and designed in the era of conventional cytotoxic drug development (Eisenhauer et al, 2000). Increasingly, they now include novel MTAs and several challenging questions need to be addressed in this context. Our retrospective analysis investigated whether there was any correlation between the potential for clinical benefit derived from Phase-I treatment and the actual dose that patients received. Patients were divided in three cohorts depending on the percentage of the final MTD of the drug received and we studied the NPR, duration of NP, and response. In summary, we did not observe any statistical differences in the NPR at 3 or 6 months and in the time of NP for the three cohorts. These results support the hypothesis that in the era of Phase-I trials studying MTAs, patients could derive prolonged disease stabilisation, and thus potential for clinical benefit even on lower dose levels; this in turn may influence the way current Phase-I cancer trials are planned, implemented, and analysed.
Our data could also have implications in the way Phase-I trials are discussed with patients before trial entry. Many patients would, if given the choice, prefer being enroled at higher dose levels rather than at lower levels, in which the dose administered is thought to be insufficient. The fact that we could not show any detriment for patients enroled at lower dose levels may result in an enhanced acceptability of entry at initial stages.

In addition, our data emphasise the importance of identifying a biologically active dose in Phase-I trials of MTA (Ratain and Glassman, 2007; Banerji et al, 2008; Cannistra, 2008), as this may be significantly different from the MTD (Slaton et al, 1999). Clinically, the most effective dose will vary across this range according to the type of agent. Generally, novel MTAs may have a broader therapeutic range compared with conventional cytotoxic agents, and clearly the use of a lower dose could limit the risk of both late and cumulative toxicities using MTAs either as single agents or in combination with conventional chemotherapy or radiotherapy (Cannistra, 2008). At this stage, however, Phase-I trials of MTAs, as well as involving detailed pharmacodynamic and pharmacokinetic analysis, should continue to have the determination of MTD as a primary aim. Subsequent decisions regarding RP2D will vary according to the agent, and randomised Phase-II trials may well be appropriate (Haines, 2008; Sleijfer and Wiemer, 2008).

An alternative conclusion from our study is that the clinical outcome in our patients was not influenced by the Phase-I trial treatment at all. Indeed, this could explain the absence of significant difference in the NPR between the three cohorts, but would not explain the fact that radiological measurable response was seen in some patients, and not exclusively at the MTD level. Nowadays, randomised Phase-II trials evaluating MTAs use, as primary objective, the PFS - or Time To Progression - to determine if the drug deserves further evaluation in a randomised Phase III setting (Korn et al, 2001; Ratain and Glassman, 2007). However, we acknowledge that the NPR at 3 and 6 months is a difficult and insufficiently validated measure of clinical benefit and that it would be strengthened by larger numbers, as well as data on symptomatic and/or performance status improvement. A potentially helpful tool to evaluate clinical benefit using PFS was proposed several years 


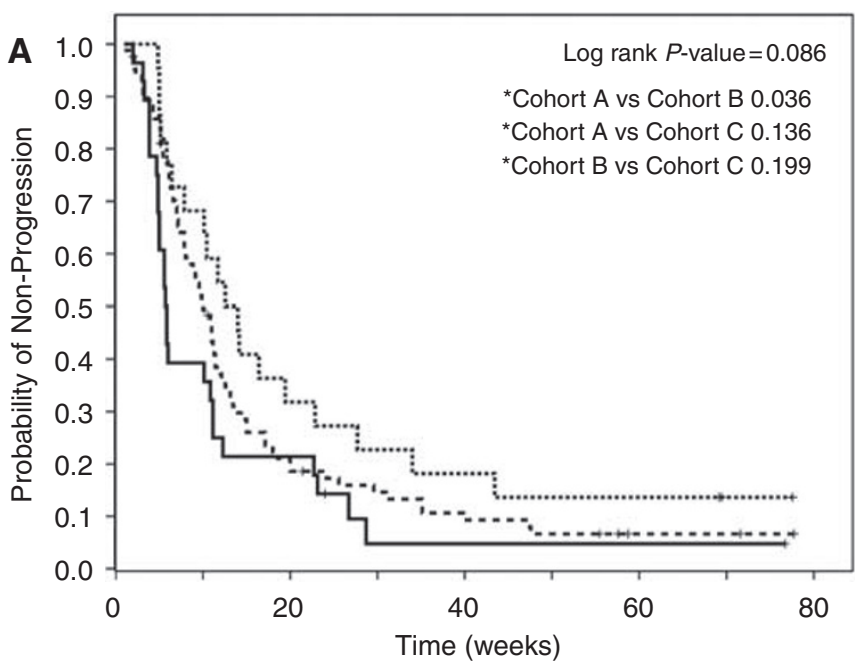

\begin{tabular}{|c|c|c|c|c|}
\hline $\mathrm{Col}$ & rt & $\mathrm{N}$ & median OS & (Cl 95\%) \\
\hline $\bar{\ldots}$ & $\begin{array}{l}\text { Cohort A } \\
\text { Cohort B } \\
\text { Cohort C }\end{array}$ & $\begin{array}{l}28 \\
22 \\
85\end{array}$ & $\begin{array}{l}6 \text { weeks } \\
13 \text { weeks } \\
10 \text { weeks }\end{array}$ & $\begin{array}{r}5-7 \\
8-17 \\
8-12\end{array}$ \\
\hline
\end{tabular}

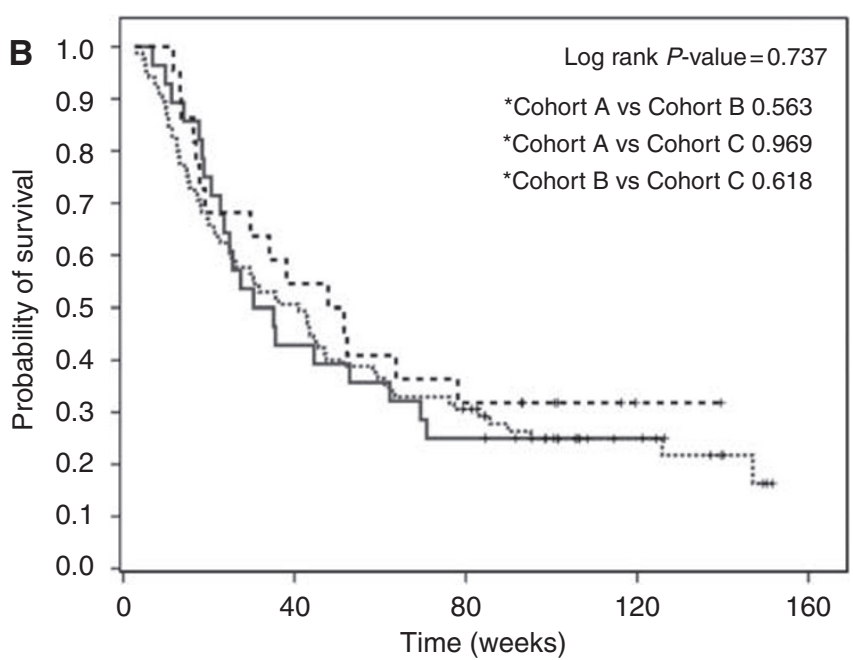

\begin{tabular}{|c|c|c|c|}
\hline Cohort & $\mathrm{N}$ & median OS & (Cl 95\%) \\
\hline Cohort A & 28 & 30 weeks & $17-43$ \\
\hline ... Cohort B & 22 & 48 weeks & $27-69$ \\
\hline ..... Cohort C & 85 & 41 weeks & $28-54$ \\
\hline
\end{tabular}

Figure 3 (A) Progression-free survival (PFS) of cohort $A, B$, and $C$. (B) Overall survival (OS) of cohort A, B, and C. ago and entitled the Growth Modulation Index (GMI) (Von Hoff, 1998; Mick et al, 2000). The GMI - defined by the ratio $\operatorname{TTP}(1)$ : $\operatorname{TTP}(2)$, in which $\operatorname{TTP}(1)$ and $\operatorname{TTP}(2)$ are, respectively, the TTP before and after starting a treatment - compares the rate of change of a tumour lesion before and after Phase-I treatment. It is suggested that a GMI $>1.3$ reflects treatment effect. Although not yet validated, we applied this methodology to a subgroup of our patients in whom radiological imaging was completely available. In our series, the GMI for patients who experienced disease control for $>6$ months was 3.1 (range 1.0-9.4), suggesting that these patients had a 'real' drug benefit, whereas patients who progressed between 3 and 6 months had a GMI of 1.1 (range $0.3-3.0 ; 15$ patients evaluable). Despite the small patient numbers and the lack of conformity of measurements of tumour progression before Phase-I trial entry, we believe that this methodology deserves further careful evaluation.

A last point to address is the fact that this data set is small and it is possible that the number of patients included in this analysis did not allow us to observe significant differences in dose response. To explore this further, we repeated this analysis by dividing the patients in two groups ( $>$ or $\leqslant 50 \%$ of the MTD), which allowed us to increase the number of patients per group. Here again, we could not see any statistically significant difference between the two groups with regards to the 3 and 6 months NPR (data not shown). We acknowledge, however, that these data, as they derive from a retrospective single-centre analysis, have to be interpreted cautiously and that our study can only allow the generation of hypotheses. Therefore, we would strongly encourage further validation in larger cohorts.

In summary, our results raise the possibility that the potential for clinical benefit, as measured by NPR and radiological responses, is not confined to patients treated at doses close to the MTD in Phase-I trials of novel MTAs. Whether a prolonged NP leads to a true clinical benefit for the patient is still unclear and deserves further careful evaluation. If validated, this could potentially impact on the discussion between clinicians and patients who are candidates for Phase-I trials. It also reinforces the need to study the biologically effective doses in addition to MTD. Further validation, in larger cohorts and revisiting Phase-I data of MTAs, which have already shown efficacy in Phase-II/III trials, is warranted.

\section{ACKNOWLEDGEMENTS}

The Drug Development Unit at RMH/ICR is supported by an Experimental Cancer Medicine Centre grant from Cancer Research UK and the Department of Health and by a programme grant from Cancer Research UK. It also received support from the Department of Health as part of the NIHR Biomedical Research Centre at RMH. Sophie Postel-Vinay is supported by a fellowship from Institut Gustave-Roussy, Villejuif, France.

\section{REFERENCES}

Agrawal M, Emanuel EJ (2003) Ethics of phase 1 oncology studies: reexamining the arguments and data. JAMA 290(8): 1075-1082

Arkenau HT, Barriuso J, Olmos D, Ang JE, de Bono J, Judson I, Kaye S (2009) Prospective validation of a prognostic score to improve patient selection for oncology Phase I trials. J Clin Oncol 27 (in press)

Banerji U, Bono J, Judson I, Kaye S, Workman P (2008) Biomarkers in early clinical trials: the committed and the skeptics. Clin Cancer Res 14(8): 2512; author reply $2513-2514$

Booth CM, Calvert AH, Giaccone G, Lobbezoo MW, Seymour LK, Eisenhauer EA (2008) Endpoints and other considerations in phase I studies of targeted anticancer therapy: recommendations from the task force on Methodology for the Development of Innovative Cancer Therapies (MDICT). Eur J Cancer 44(1): 19-24

Bubley GJ, Carducci M, Dahut W, Dawson N, Daliani D, Eisenberger M, Figg WD, Freidlin B, Halabi S, Hudes G, Hussain M, Kaplan R, Myers C, Oh W, Petrylak DP, Reed E, Roth B, Sartor O, Scher H, Simons J, Sinibaldi V, Small EJ, Smith MR, Trump DL, Wilding G (1999) Eligibility and response guidelines for phase II clinical trials in androgenindependent prostate cancer: recommendations from the ProstateSpecific Antigen Working Group. J Clin Oncol 17(11): 3461-3467 
Cannistra SA (2008) Challenges and pitfalls of combining targeted agents in phase I studies. J Clin Oncol 26(22): 3665-3667

Eisenhauer EA, O’Dwyer PJ, Christian M, Humphrey JS (2000) Phase I clinical trial design in cancer drug development. J Clin Oncol 18(3): 684-692

Haines IE (2008) Dose selection in phase I studies: why we should always go for the most effective. J Clin Oncol 26(21): 3650-3652; author reply $3652-3653$

Itoh K, Sasaki Y, Miyata Y, Fujii H, Ohtsu T, Wakita H, Igarashi T, Abe K (1994) Therapeutic response and potential pitfalls in phase I clinical trials of anticancer agents conducted in Japan. Cancer Chemother Pharmacol 34(6): $451-454$

Korn EL, Arbuck SG, Pluda JM, Simon R, Kaplan RS, Christian MC (2001) Clinical trial designs for cytostatic agents: are new approaches needed? J Clin Oncol 19(1): 265-272

Koyfman SA, Agrawal M, Garrett-Mayer E, Krohmal B, Wolf E, Emanuel EJ, Gross CP (2007) Risks and benefits associated with novel phase 1 oncology trial designs. Cancer 110(5): 1115-1124

Mick R, Crowley JJ, Carroll RJ (2000) Phase II clinical trial design for noncytotoxic anticancer agents for which time to disease progression is the primary endpoint. Control Clin Trials 21(4): 343-359

Parulekar WR, Eisenhauer EA (2004) Phase I trial design for solid tumor studies of targeted, non-cytotoxic agents: theory and practice. J Natl Cancer Inst 96(13): $990-997$
Potter DM (2002) Adaptive dose finding for phase I clinical trials of drugs used for chemotherapy of cancer. Stat Med 21(13): 1805-1823

Ratain MJ, Glassman RH (2007) Biomarkers in Phase I oncology trials: signal, noise, or expensive distraction? Clin Cancer Res 13(22 Pt 1): $6545-6548$

Slaton JW, Perrotte P, Inoue K, Dinney CP, Fidler IJ (1999) Interferonalpha-mediated down-regulation of angiogenesis-related genes and therapy of bladder cancer are dependent on optimization of biological dose and schedule. Clin Cancer Res 5(10): 2726-2734

Sleijfer S, Wiemer E (2008) Dose selection in phase I studies: why we should always go for the top. J Clin Oncol 26(10): 1576-1578

Therasse P, Arbuck SG, Eisenhauer EA, Wanders J, Kaplan RS, Rubinstein L, Verweij J, Van Glabbeke M, van Oosterom AT, Christian MC, Gwyther SG (2000) New guidelines to evaluate the response to treatment in solid tumors. European Organization for Research and Treatment of Cancer, National Cancer Institute of the United States, National Cancer Institute of Canada. J Natl Cancer Inst 92(3): 205-216

Von Hoff DD, Turner J (1991) Response rates, duration of response, and dose response effects in phase I studies of antineoplastics. Invest New Drugs 9(1): $115-122$

Von Hoff DD (1998) There are no bad anticancer agents, only bad clinical trial designs-twenty-first Richard and Hinda Rosenthal Foundation Award Lecture. Clin Cancer Res 4(5): 1079-1086 